\title{
A new path for the Journal of the Foot \& Ankle - JFA
}

\begin{abstract}
Hard work is the key to success. It may sound like a cliché, but the preparation and the release of this first edition of the new Journal of the Foot \& Ankle (JFA) were based on this very concept, and we took it very seriously! For years many of us have dedicated time and efforts to bring this Journal to life. After countless meetings, discussions, phone calls, WhatsApp messages, and an infinite amount of writing, our collaborative hard work and friendship finally brought us here!
\end{abstract}

Now we need to stay focused and ahead of the game, looking forward to the future and the innovations. We should aim to publish high-quality, unbiased research, with emphasis on strong clinical evidence.

Our vision is to support researchers and research that can enable the Orthopaedic Foot and Ankle Surgery Community to understand better the complexity of the pathologies, guide treatment, and, most importantly, improve the treatment results and quality of life of our patients. Our thoughts are that keeping all these goals in mind will allow us to achieve the expected acceptance and respect of the research community, as well as the desired indexation. It is not an easy task! But we are confident we can get there with your help!

We're great believers in working as a team towards a common goal, and we are sure that with the help of our dedicated Foot and Ankle colleagues and researchers, we will soon make our vision become a reality! Let's do it together!

EDITOR-IN-CHIEF
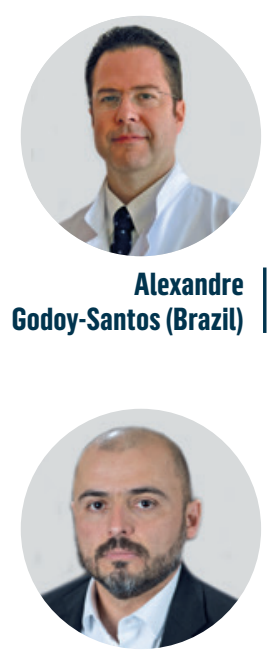

Marco Túlio Costa

(Brazil)
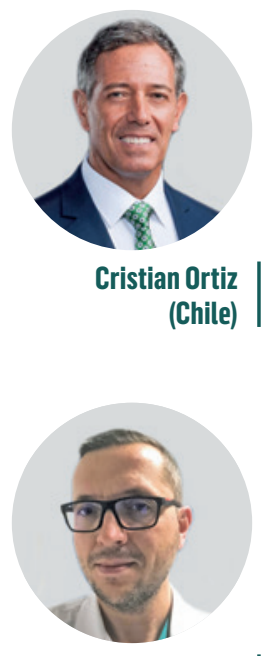

Mario Herrera

(Spain)

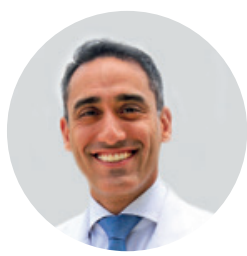

Daniel Baumfeld (Brazil)

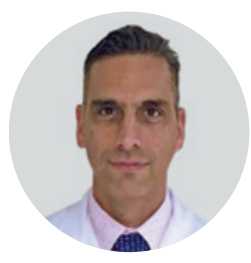

Pablo Sotelano (Argentina)
ASSOCIATE EDITORS
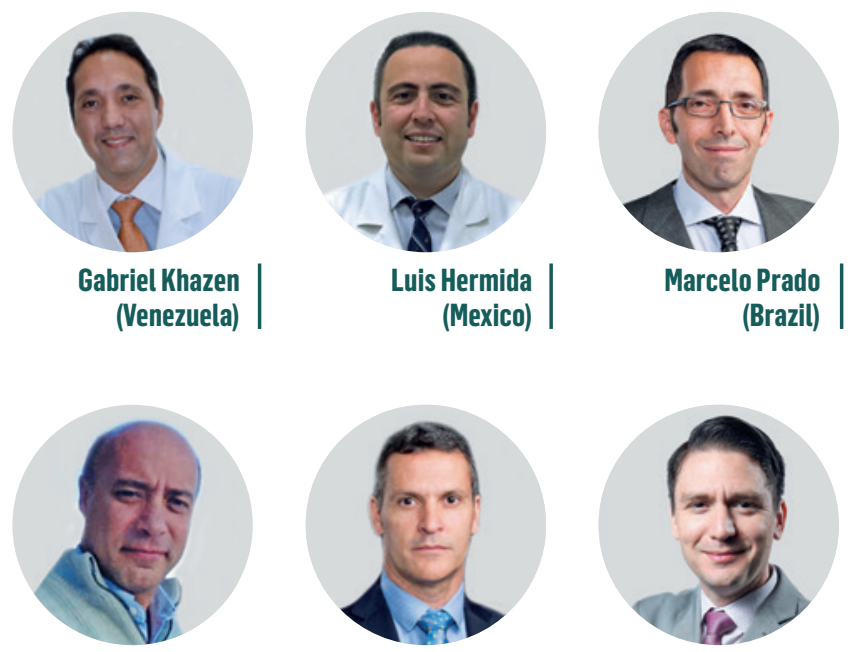

Paulo Felicissimo (Portugal)

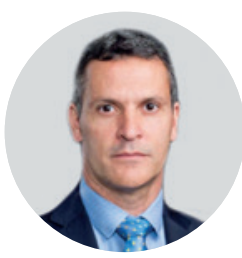

Santiago Guerrero

(Colombia)

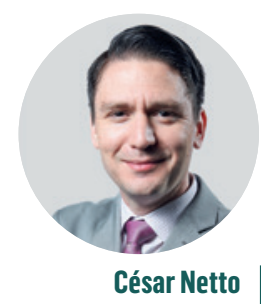

(USA) 


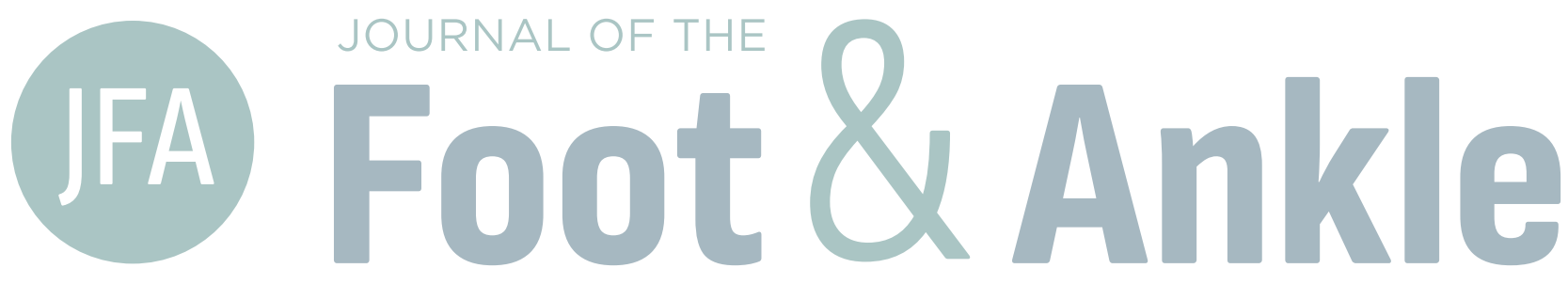

